\title{
Modulation of the regression of atherosclerosis in the hamster by dietary lipids: comparison of coconut oil and olive oil
}

\author{
E. Heather Mangiapane ${ }^{1}$, Martina A. McAteer ${ }^{1}$, G. Martin Benson ${ }^{2}$, David A. White ${ }^{3}$ and \\ Andrew M. Salter ${ }^{1 *}$ \\ ${ }^{1}$ Division of Nutritional Biochemistry, School of Biological Sciences, University of Nottingham, Sutton Bonington Campus, \\ Loughborough LE12 5RD, UK \\ ${ }^{2}$ Vascular Biology Department, SmithKline Beecham Pharmaceuticals Ltd, Harlow, Essex CM19 5AW, UK \\ ${ }^{3}$ School of Biomedical Sciences, University of Nottingham Medical School, Nottingham NG7 2UH, UK
}

(Received 10 September 1998 - Revised 11 May 1999 - Accepted 31 May 1999)

\begin{abstract}
The Golden Syrian hamster (Mesocricetus auratus) has been shown to be a useful model of both human lipoprotein metabolism and the development of atherosclerosis. We report the effects of dietary lipids on the progression and regression of atherosclerosis in this model. In the first study, hamsters fed on coconut oil ( $150 \mathrm{~g} / \mathrm{kg}$ diet $)$ and cholesterol $(30 \mathrm{~g} / \mathrm{kg}$ diet $)$ developed lipid-rich lesions in the ascending aorta $\left(0.28(\mathrm{SD} 0.14) \mathrm{mm}^{2}\right)$ and aortic arch $\left(0.01(\mathrm{SD} 0.01) \mathrm{mm}^{2}\right)$ after 4 weeks that continued to progress over the next 8 weeks $(0.75$ (SD 0.41$) \mathrm{mm}^{2}$ and 0.12 (SD $0 \cdot 11) \mathrm{mm}^{2}$ for the ascending aorta and aortic arch respectively). Removal of cholesterol from the diet halted this progression. Furthermore, in animals fed on olive oil in the absence of added cholesterol, plasma LDL-cholesterol concentrations were lower $(P<0.05)$ and the extent of atherosclerotic lesions was reduced $(P<0.001$ for both regions of the aorta) compared with animals fed on coconut oil (with no added cholesterol). In a second study, animals were fed on the atherogenic diet for 10 weeks, transferred to diets containing either coconut oil ( $150 \mathrm{~g} / \mathrm{kg} \mathrm{diet})$ or olive oil $(150 \mathrm{~g} / \mathrm{kg}$ diet $)$ without added cholesterol and monitored for up to 16 weeks. In the ascending aorta, lesion size doubled in animals fed on coconut oil but stabilized in those fed on olive oil. In the aortic arch, lesion size decreased linearly $(P<0.05, P<0.001$ for coconut oil and olive oil respectively) with the greatest reduction being seen in the olive-oil-fed animals $(P<$ 0.05). Again, progression and regression of atherosclerosis appeared to reflect the relative concentrations of LDL-cholesterol and HDL-cholesterol in the plasma. We conclude that the male Golden Syrian hamster represents a useful model of dietary induced regression as well as progression of atherosclerosis.
\end{abstract}

Hamster: Atherosclerosis: Coconut oil: Olive oil: Dietary fat

The Golden Syrian hamster (Mesocricetus auratus) has been used extensively in studies of lipoprotein metabolism. We (Sessions \& Salter, 1994; Bennett et al. 1995; White et al. 1997; Salter et al. 1998) and others (Spady \& Dietschy, 1988; Woollett et al. 1989, 1992; Lindsey et al. 1990) have shown this species to be useful in studying the lipoprotein response to dietary cholesterol and lipids. The extensive studies of Spady, Dietschy and co-workers clearly demonstrated changes in the kinetics of LDL metabolism in response to different dietary fats (Spady et al. 1993). We have recently shown that these changes may, at least in part, be due to changes in the hepatic expression of genes such as LDL receptor, apolipoprotein $\mathrm{B}$ and the microsomal triacylglycerol (TAG) transfer protein (White et al. 1997; Salter et al. 1998). The hamster has also been used for the study of development of atherosclerosis (Nistor et al. 1987; Sima et al. 1990). Nistor et al. (1987) performed detailed histological studies of the development of aortic atherosclerosis in response to diets enriched in cholesterol and saturated fat. Lesions appeared after only 3 weeks. Humanlike lesions, displaying $\mathrm{Ca}$ deposits and necrosis, had developed by 10 months. Other workers have demonstrated inhibition of the development of atherosclerosis using a range of pharmacological agents including: hydroxymethylglutaryl-CoA reductase (EC 1.1.1.34) inhibitors (Otto et al. 1995), bile-acid-binding resins (Kowala et al. 1991), prostacyclin agonists (Kowala et al. 1993) and $\alpha_{1}$ adrenergic inhibitors (Kowala et al. 1991; Foxall et al. 1992). These studies have used various strains of hamster and a range of dietary interventions to induce atherosclerosis. Some strains 
require high levels of dietary cholesterol (up to $30 \mathrm{~g} / \mathrm{kg}$ diet) to develop atherosclerotic lesions (Nistor et al. 1987; Sima et al. 1990), although the amount of cholesterol required may depend on the amount of saturated fatty acid in the diet (Kahlon et al. 1996). By contrast, the $\mathrm{F}_{1} \mathrm{~B}$ hybrid strain of hamster has been shown to develop aortic fatty streaks when fed on diets with cholesterol concentrations as low as 0.5 $\mathrm{g} / \mathrm{kg}$ (Kowala et al. 1991). In the DSNI strain we have found that a minimum of $5 \mathrm{~g}$ cholesterol $/ \mathrm{kg}$ diet is required to induce aortic lesions (MA McAteer, GM Benson and AM Salter, unpublished results).

Considerable evidence exists to suggest that atherosclerotic lesions can regress in human subjects (Mahler, 1995). However, detailed studies of regression are frequently hampered by choice of animal model and the length of the experiments required. Studies with swine and non-human primates have clearly shown that reduction in plasma lipids, by dietary or pharmacological means, can result in the regression of advanced atherosclerotic plaques (Wissler \& Vesselinovitch, 1990). However, such studies can take many years to perform (Strong et al. 1994). The normal rabbit (Vesselinovitch et al. 1974; Zhu et al. 1990, 1994) and the Watanabe heritable hyperlipidaemic rabbit (Oshima et al. 1998) have been used in regression studies. However, a smaller animal model of regression would be very valuable for further studies of the mechanisms of regression and the efficacy of potential pharmacological and dietary interventions. Regression of atherosclerosis was recently reported in the hamster (Pitman et al. 1998). Such a small animal model of regression could be extremely useful in furthering our understanding of the mechanisms of regression and the potential effects of dietary and pharmacological interventions. In the present study we performed two trials. The first, lasting a total of 12 weeks, was primarily designed to determine whether by removing cholesterol from the diet and changing from a saturated-fatty-acid-rich to a monounsaturated-fattyacid-rich diet differences in the progression of atherosclerosis could be detected. A second longer (total of 26 weeks) trial was performed to look at the effect of these diets on the regression of atherosclerotic lesions.

\section{Materials and methods}

\section{Animals and diets}

All procedures involving animals in these studies were subject to UK Home Office regulations.

Study 1. Thirty-two 16-24-week-old (weight 134$175 \mathrm{~g}$ ) male DSNI Golden Syrian Hamsters (Biomedical Services Unit, University of Nottingham, Notts., UK) were housed individually and provided free access to food and water. They were maintained in a controlled environment $\left(21^{\circ}, 55 \%\right.$ humidity $)$ and were subjected to a $12 \mathrm{~h}$ lightdark cycle. On arrival at our facility animals were allowed a 2-week acclimatization period during which they were fed on a commercial rodent chow (Rat and Mouse Breeding Diet No. 3, Special Diet Services, Chelmsford, Essex, UK). During the first week this diet was provided in pelleted form and in the second week as a ground meal. Following the acclimatization period all animals were transferred to an atherogenic diet consisting of $(\mathrm{g} / \mathrm{kg})$ : Rat and Mouse Breeding Diet No. 3 820, coconut oil (Sigma, Poole, Dorset, UK) 150 and cholesterol (Sigma) 30. All animals were checked daily for signs of ill-health throughout the trial and body weights were checked weekly. No animal lost more than $10 \%$ of its initial body weight. After 4 weeks on the atherogenic diet, eight animals were randomly selected, (group A), fasted overnight and killed the following morning. They were anaesthetized using sodium pentabarbitone (Sagatal, $1 \mathrm{ml} / \mathrm{kg}$ ) and $3-4 \mathrm{ml}$ blood collected by cardiac puncture and placed into EDTA-tubes. The aortas were then dissected from the animals, flushed with saline and fixed in $10 \%$ neutral buffered formalin (Sigma).

The remaining animals were randomly allocated to three groups of eight. Group B continued to be fed on the atherogenic diet, group $\mathrm{C}$ was fed on $(\mathrm{g} / \mathrm{kg}$ diet): chow 850 , coconut oil (no added cholesterol) 150 and group D was fed on $(\mathrm{g} / \mathrm{kg}$ diet): chow 850 , extra virgin olive oil (Filippo Berio, Lucca, Italy) with no added cholesterol 150. After a further 8 weeks all animals were killed and samples taken as described earlier.

Study 2. Thirty male, 12-18-week-old (weight 100$140 \mathrm{~g}$ ), DSNI hamsters were housed as described earlier. During the acclimatization period they were fed on Rat and Mouse Breeding Diet 422 (Pilsbury, Northants, UK) and this chow was also used in the experimental diets. Both this chow and that used in study 1 are rodent breeding diets with similar overall compositions (gross energy, $15 \cdot 3$ v. $16 \cdot 0 \mathrm{MJ} /$ $\mathrm{kg}$; crude oil, 43 v. $44 \mathrm{~g} / \mathrm{kg}$; crude protein, 223 v. $209 \mathrm{~g} / \mathrm{kg}$; crude fibre, $45 v .41 \mathrm{~g} / \mathrm{kg}$ and starch, $358 v .362 \mathrm{~g} / \mathrm{kg}$ for the Special Diet Services and Pilsbury diets respectively). For the first 10 weeks all animals were fed on an atherogenic diet similar to that described earlier, except that hydrogenated coconut oil (ICN Biomedicals Ltd, Thame, Oxon., UK) rather than coconut oil was used. This was used to enhance the atherogenicity of the diet as it is even richer in saturated fatty acids (see Table 1). After 10 weeks, a group of six animals was randomly selected and killed as before (group A). The remaining twenty-four animals were allocated to two groups of twelve, one of which was fed on a diet containing $(\mathrm{g} / \mathrm{kg}$ diet): chow 850 and hydrogenated coconut oil 150 and the other a diet containing chow 850 and olive oil 150 (both with no added cholesterol). After a further 8 weeks, six coconut-oil-fed animals and six

Table 1. Fatty acid composition of dietary oils ( $\mathrm{g} / 100 \mathrm{~g}$ total fatty acids recovered)

\begin{tabular}{|c|c|c|c|c|c|c|c|c|}
\hline Fatty acid... & $8: 0$ & $10: 0$ & $12: 0$ & $14: 0$ & $16: 0$ & $18: 0$ & $18: 1$ & $18: 2$ \\
\hline Coconut oil & 4.5 & 7.9 & $32 \cdot 8$ & $24 \cdot 0$ & $13 \cdot 3$ & $4 \cdot 2$ & $10 \cdot 3$ & $3 \cdot 1$ \\
\hline Hydrogenated coconut oil & $5 \cdot 0$ & 7.5 & $32 \cdot 4$ & 24.5 & $13 \cdot 6$ & $15 \cdot 0$ & 0.8 & 0.7 \\
\hline Olive oil & ND & ND & ND & ND & 11.8 & 3.7 & $73 \cdot 2$ & $8 \cdot 2$ \\
\hline
\end{tabular}

ND, not detected. 
olive-oil-fed animals (groups B and C respectively) were killed. After another 8 weeks the remaining six coconut-oilfed (group D) and six olive-oil-fed (group E) animals were killed.

\section{Fatty acid analysis of dietary fats}

Coconut oil, hydrogenated coconut oil and olive oil were extracted, transmethylated and analysed by GLC as previously described (Bennett et al. 1995).

\section{Separation of lipoproteins}

Lipoprotein fractions were separated from plasma (normally $1 \mathrm{ml}$ ) by sequential ultracentrifugation and corrected for recovery (typically $>85 \%$ ) as previously described (Salter et al. 1998). VLDL, intermediate-density lipoprotein (IDL), LDL and HDL were separated with the density ranges $<1.006, \quad 1.006-1.020,1.020-1.060$ and $>1.060 \mathrm{~g} / \mathrm{ml}$ respectively. Cholesterol and TAG concentrations in whole plasma and lipoprotein fractions were determined using diagnostic kits from Wako (Alpha Laboratories, Eastleigh, Hants., UK).

\section{Determination of the extent of atherosclerosis}

The fixed aortas were cleared of adventitial tissue and rinsed in distilled water. They were then rinsed in propan-2-ol $(600 \mathrm{ml} / \mathrm{l})$ before staining with Oil Red O-propan-2-ol $(10: 90, \mathrm{v} / \mathrm{v})$ for $15 \mathrm{~min}$. The tissue was destained with propan-2-ol and then distilled water before returning to neutral buffered formalin. For quantification of lipid staining, the aorta was cut open along the outer curvature, laid flat on a glass slide and held in place with a cover slip. The aorta was then examined under a stereo microscope and separate images of the ascending aorta and aortic arch captured using Optimas Imaging System Software (version 5.2, Data Cell Ltd, Maidenhead, Berks., UK). Essentially all of the lipid staining in the ascending aorta was located in proximity to the aortic valve. The arch was identified as the region between the left and right subclavian arteries. The total area of Oil-Red-O staining was determined for both regions of the aorta.

\section{Statistical analysis}

Data for each variable in each study were checked for Gaussian distribution. Plasma lipid and lipoprotein concentrations were found generally not to be normally distributed, in many cases even after log-transformation, and were therefore analysed by non-parametric tests. Data were analysed by either: one-way ANOVA (followed by either Tukey-Kramer multiple comparisons test or Bonferroni (selected pairs) test as appropriate) or Kruskal-Wallis nonparametric ANOVA test (followed by Dunn's multiple comparisons test) using In Stat software (GraphPad, San Diego, CA, USA). The specific statistical test applied is indicated in the legends to tables and figures. Correlations were calculated using the non-parametric Spearman rank correlations using In Stat software.

\section{Results \\ Study 1}

Animals tolerated each of the diets well and no animal lost more than $10 \%$ of its initial body weight. Fasting final body

Table 2. Plasma total lipids and lipoprotein cholesterol concentrations (mmol/l) in animals from study $1 \dagger$

(Values are medians and interquartile ranges for eight animals per group)

\begin{tabular}{|c|c|c|c|c|c|c|c|c|c|}
\hline Group... & \multicolumn{2}{|r|}{ A } & \multicolumn{2}{|c|}{ B } & \multicolumn{2}{|r|}{ C } & \multicolumn{2}{|c|}{$\mathrm{D}$} & \multirow{4}{*}{$\begin{array}{c}\text { Statistical } \\
\text { significance } \\
\text { of difference } \\
\text { between } \\
\text { meansł; } P\end{array}$} \\
\hline Time from start (weeks) ... & & 4 & & 2 & & 12 & & 12 & \\
\hline \multirow[t]{2}{*}{ Diet... } & \multicolumn{2}{|c|}{$\mathrm{CO}+\mathrm{Chol}$} & \multicolumn{2}{|c|}{$\mathrm{CO}+\mathrm{Chol}$} & \multicolumn{2}{|c|}{$\mathrm{CO}$} & \multicolumn{2}{|c|}{$\mathrm{OO}$} & \\
\hline & Median & $\begin{array}{l}\text { Interquartile } \\
\text { range }\end{array}$ & Median & $\begin{array}{l}\text { Interquartile } \\
\text { range }\end{array}$ & Median & $\begin{array}{l}\text { Interquartile } \\
\text { range }\end{array}$ & Median & $\begin{array}{l}\text { Interquartile } \\
\text { range }\end{array}$ & \\
\hline Total cholesterol & $11 \cdot 18$ & $8.89-12.08$ & $19 \cdot 47$ & $18.58-21.02$ & 8.98 & $7.94-11.48$ & 4.91 & $4 \cdot 62-5.14$ & $\begin{array}{l}\text { Group C v. B, }{ }^{*} \\
\text { Group D v. A, }{ }^{*} \\
\text { Group D v. B, }{ }^{* * *}\end{array}$ \\
\hline Total TAG & $2 \cdot 37$ & $1 \cdot 70-3 \cdot 17$ & 3.47 & $2 \cdot 76-4 \cdot 23$ & 2.08 & $1 \cdot 67-2 \cdot 26$ & 1.67 & $1.57-1.79$ & Group D v. B, ** \\
\hline VLDL-cholesterol & $2 \cdot 54$ & $1.92-3.60$ & 3.84 & $2 \cdot 94-5.37$ & 0.96 & $0.72-1.23$ & 0.87 & $0.75-0.99$ & $\begin{array}{l}\text { Group C v. B, }{ }^{* *} \\
\text { Group D v. A, } \\
\text { Group D v. B, }{ }^{* * *}\end{array}$ \\
\hline IDL-cholesterol & $2 \cdot 67$ & $1.32-2.99$ & $4 \cdot 29$ & $3.78-5 \cdot 34$ & 0.87 & $0.69-1.64$ & 0.05 & $0-0.24$ & $\begin{array}{l}\text { Group C v. B, }{ }^{*} \\
\text { Group D v. A, }{ }^{* *} \\
\text { Group D v. B, }{ }^{* * *}\end{array}$ \\
\hline LDL-cholesterol & $2 \cdot 19$ & $0.77-3 \cdot 85$ & $6 \cdot 99$ & $5 \cdot 36-8 \cdot 64$ & $4 \cdot 68$ & $3 \cdot 22-5 \cdot 16$ & 0.48 & $0.42-0.60$ & $\begin{array}{l}\text { Group B v. A, }{ }^{* *} \\
\text { Group D v. B, }{ }^{* * *} \\
\text { Group D v. C, }{ }^{*}\end{array}$ \\
\hline HDL-cholesterol & $2 \cdot 78$ & $2 \cdot 50-3.68$ & 3.92 & $3 \cdot 35-4 \cdot 35$ & $3 \cdot 14$ & $2 \cdot 75-3 \cdot 43$ & 3.30 & $3.00-3.72$ & \\
\hline
\end{tabular}


weights for each of the dietary groups were $(\mathrm{g})$ : group A 159.7 (SD 13.1), group B 156.8 (SD 8.7), group C 154.5 (SD 12.4) and group D $172 \cdot 4$ (SD 9.8). Groups C and D were significantly different $(P<0 \cdot 05)$. Plasma and lipoprotein lipid concentrations in the animals from study 1 are shown in Table 2. After 4 weeks on the atherogenic diet (group A) the total plasma cholesterol and TAG concentrations were approximately 5- and 2.5-times higher than values obtained from animals of the same strain fed on chow alone (cholesterol 2.19 (SD 0.27) mmol/l, TAG 1.09 (SD 0.27) mmol/l, $n$ 4; AM Salter, unpublished results). After another 8 weeks on the high-fat, high-cholesterol diet (group B) there was a

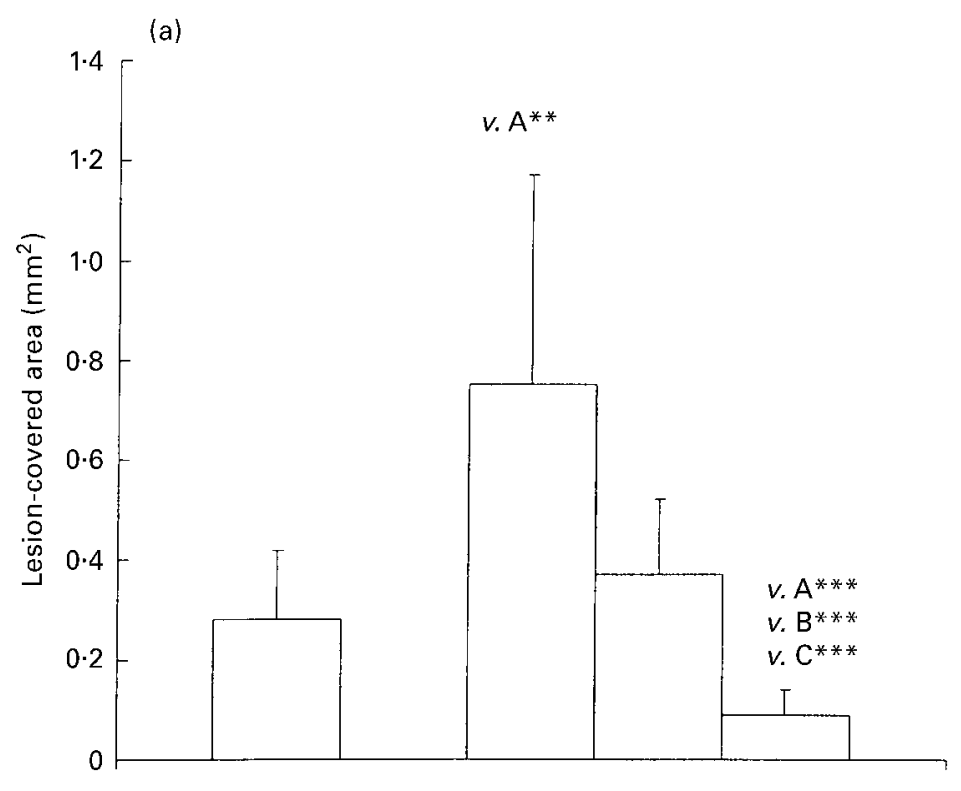

(b)

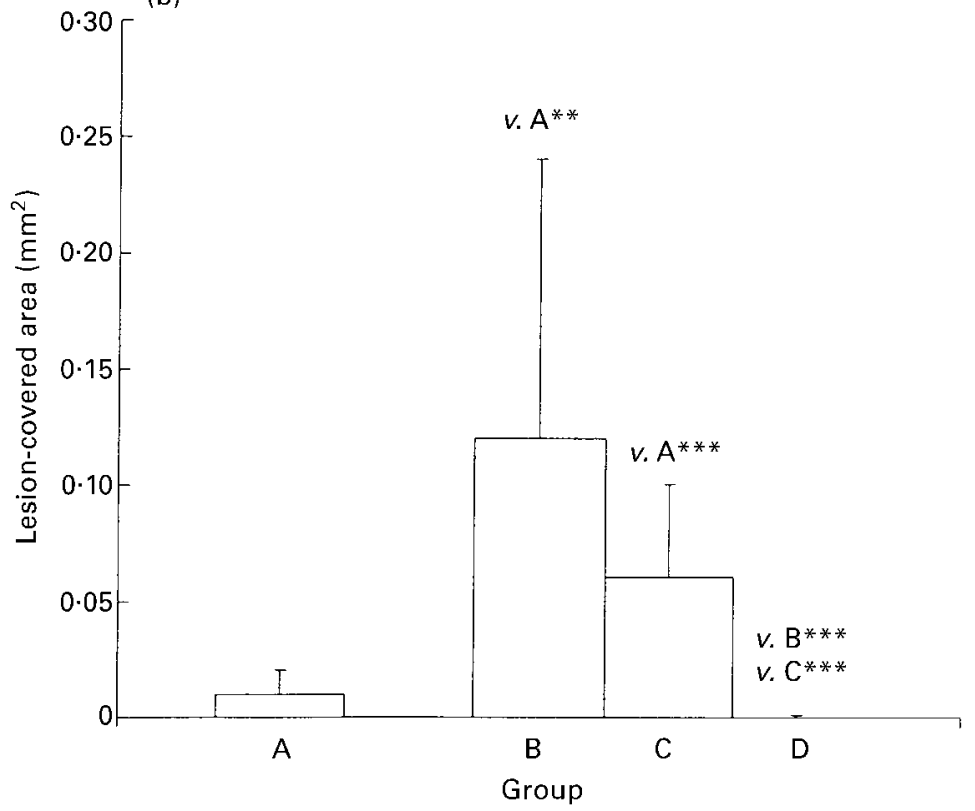

Fig. 1. Atherosclerosis in (a) ascending aorta and (b) aortic arch in hamsters from study 1 . Animals were fed on $150 \mathrm{~g}$ coconut oil $/ \mathrm{kg}$ diet and $30 \mathrm{~g}$ cholesterol $/ \mathrm{kg}$ diet for 4 weeks (group A, $n 8$ ) or 12 weeks (group B, $n 8$ ), or were transferred after 4 weeks onto cholesterol-free diets containing either $150 \mathrm{~g}$ coconut oil/kg diet (group C, $n 8$ ) or $150 \mathrm{~g}$ olive oil/kg diet (group D, $n 8$ ) and fed for a further 8 weeks. On killing the aortas were removed and stained with Oil Red $O$ as described on p. 403. Data are presented as mean values with standard deviations represented by vertical bars. Significant differences between groups were determined by ANOVA followed by Bonferroni multiple comparisons test: ${ }^{\star *} P<0.01,{ }^{\star \star *} P<0.001$. 
Table 3. Spearman rank correlations between plasma lipoprotein concentration and extent of aortic lipid staining in animals fed on experimental diets for 12 weeks (groups B, C and D) in study $1^{*}$

\begin{tabular}{|c|c|c|c|c|}
\hline & \multicolumn{4}{|c|}{ Study 1 (n 24) } \\
\hline & \multicolumn{2}{|c|}{ Ascending aorta } & \multicolumn{2}{|c|}{ Aortic arch } \\
\hline & $r$ & $P$ & $r$ & $P$ \\
\hline VLDL-cholesterol & 0.541 & 0.008 & 0.478 & 0.0 \\
\hline IDL-cholesterol & 0.644 & $<0.001$ & 0.789 & $<0.0$ \\
\hline LDL-cholesterol & 0.568 & 0.005 & 0.713 & $<0.0$ \\
\hline HDL-cholesterol & -0.045 & 0.837 & 0.189 & 0.37 \\
\hline IDL :HDL & 0.671 & $<0.001$ & 0.796 & $<0.001$ \\
\hline LDL : HDL & 0.664 & $<0.001$ & 0.688 & $<0.001$ \\
\hline
\end{tabular}

IDL, intermediate-density lipoprotein.

*For details of diets and procedures see pp. 402-403.

further 3-fold rise in the LDL-cholesterol concentration. However, when coconut oil was fed in the absence of added dietary cholesterol (group C), there was a highly significant $(P<0.01)$ drop in the cholesterol concentration in the VLDL fraction compared with groups A and B. Total plasma cholesterol and IDL-cholesterol were also reduced compared with the animals which had been on the atherogenic diet for the full 12 weeks (group B). Replacing the coconut oil with olive oil (with no added cholesterol) reduced the mean cholesterol content in each of the lipoprotein fractions, except HDL, compared with group A. The only statistically significant difference between groups $\mathrm{C}$ and $\mathrm{D}$ was a 7 -fold difference in the LDL fraction.

Fig. 1 shows the extent of positive lipid staining in the ascending aorta and aortic arch of animals in each group. All animals in group A showed some signs of atherosclerosis in both regions of the vessel. However, area of positive lipid staining was considerably greater in the ascending aorta $\left(0.28(\mathrm{SD} 0.14) \mathrm{mm}^{2}\right)$ than in the $\operatorname{arch}\left(0.01(\mathrm{SD} 0.01) \mathrm{mm}^{2}\right)$. After a further 8 weeks on the atherogenic diet the animals in group B showed a significant increase in area of positive lipid staining in both regions of the aorta $(0.75$ (SD 0.41$)$ and $\left.0.12(\mathrm{SD} 0 \cdot 11) \mathrm{mm}^{2}\right)$ for the ascending aorta and aortic arch respectively. This increase was prevented by feeding the coconut-oil-rich diet without added cholesterol (group C). Feeding olive oil without added cholesterol (group D) reduced the area covered by lesions in the ascending aorta (0.09 (SD 0.05$\left.) \mathrm{mm}^{2}\right)$ compared with the other three groups $(P<0.001)$.

To investigate whether the extent of atherosclerosis could be associated with the plasma concentrations of one particular lipoprotein fraction, correlations were performed on data from all of the animals fed for 12 weeks. Table 2 shows strong correlations between atherosclerosis in both regions of the aorta and VLDL-, IDL- and LDL-cholesterol. While there is some indication that this correlation may be stronger for IDL and LDL than VLDL, the data should be interpreted with caution because of the high degree of inter-correlation between the fractions. HDL-cholesterol was not significantly correlated to the degree of atherosclerosis and expressing IDL or LDL as a ratio against HDL did not improve the correlations significantly.

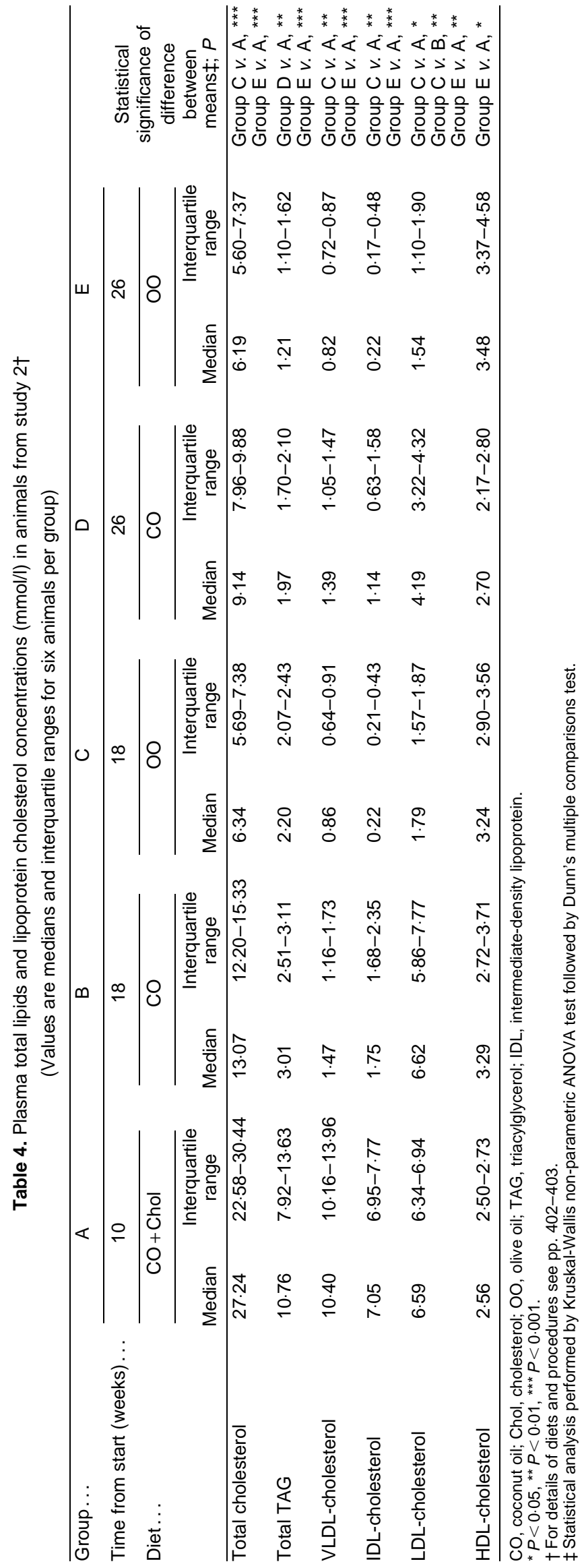




\section{Study 2}

In order to confirm the ability of the olive-oil-rich diets to induce regression of the atherosclerotic lesions, a second study was performed in which animals were fed on an atherogenic diet for longer (10 as opposed to 4 weeks) before transfer to the low-cholesterol diets. Animals in this study were somewhat younger than those used in the first study and this was reflected in starting body weights. No significant difference was seen in fasting final body weight between any of the dietary groups (g): group A 120.2 (SD 4.7), group B 128.5 (SD 10.1), group C 135.9 (SD 10.8), group D 134.2 (SD 7.8) and group E 131.1 (SD 16.8). However, it is of note that the animals never achieved the
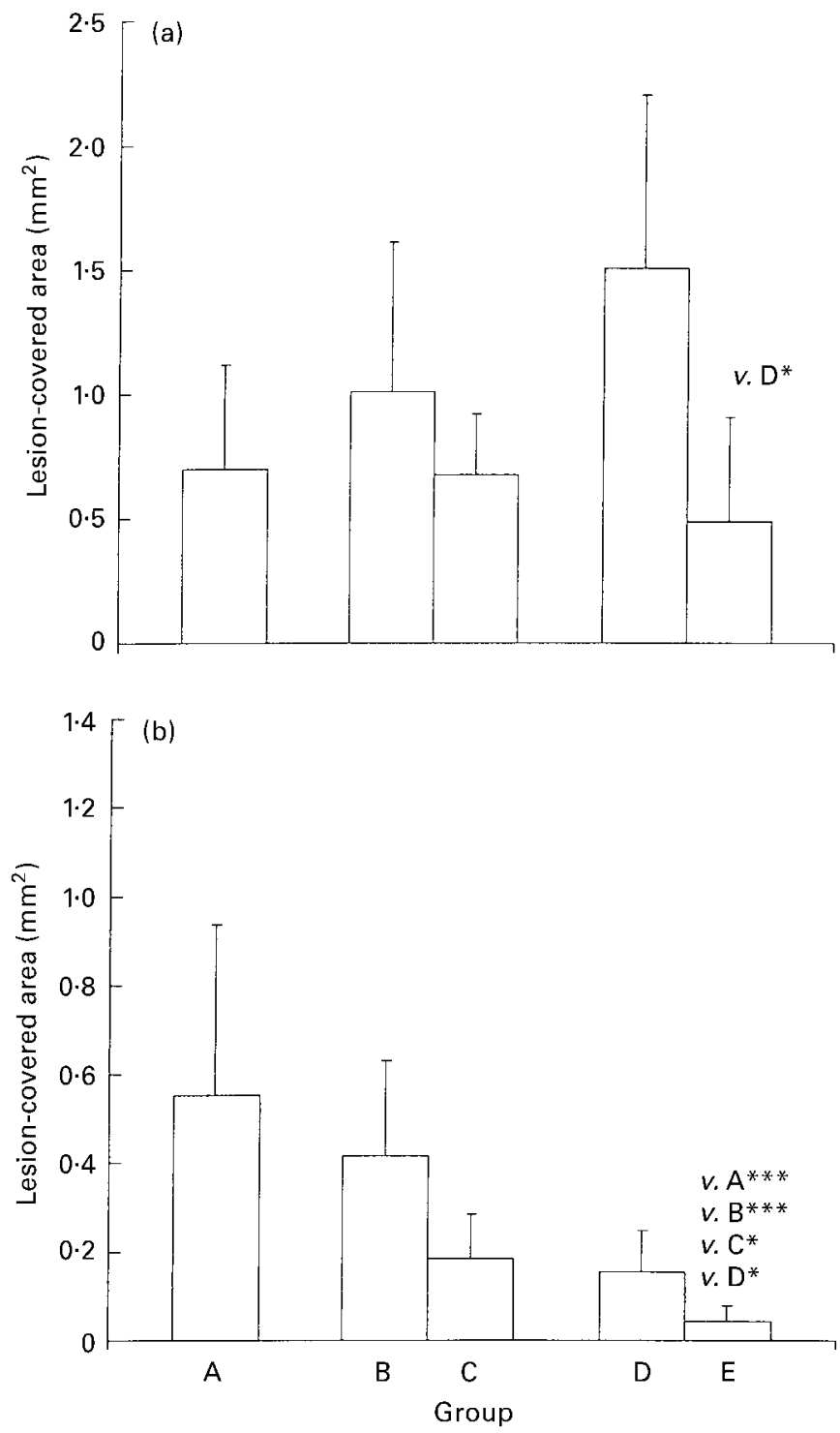

Fig. 2. Atherosclerosis in (a) ascending aorta and (b) aortic arch in hamsters from study 2 . Thirty male hamsters were fed on a diet containing $150 \mathrm{~g}$ hydrogenated coconut oil $/ \mathrm{kg}$ diet and $30 \mathrm{~g}$ cholesterol $/ \mathrm{kg}$ diet for 10 weeks. At the end of this period six animals were killed (group A) and the remainder were transferred onto cholesterol-free diets containing either $150 \mathrm{~g}$ hydrogenated coconut oil $/ \mathrm{kg}$ (groups B and D) or $150 \mathrm{~g}$ olive oil/kg (groups $C$ and $E$ ). Groups of six animals were killed after a further 8 weeks (groups B and C) and 16 weeks (groups D and E). The aortas were removed and stained with Oil Red $O$ as described on pp. 402-403. Data are presented as mean values with standard deviations represented by vertical bars. For data from the ascending aorta significant differences between groups were determined by ANOVA followed by Bonferroni multiple comparisons test. Data from the aortic arch were not normally distributed and were first log-transformed before statistical analysis: ${ }^{*} P<0.05,{ }^{* *} P<0.001$. 
body weights seen in study 1 , despite the fact that the trial lasted up to 14 weeks longer. Total plasma cholesterol and TAG (Table 3) were considerably higher in the animals fed on the atherogenic diet for 10 weeks (group A) than for animals fed on the same diet for 12 weeks in the previous study (group B). This was almost entirely due to a $2 \cdot 5$-fold higher concentration of VLDL-cholesterol in the second trial. VLDL- and IDL-cholesterol dropped dramatically when cholesterol was omitted from the diet, with the fall being greatest in the olive-oil-fed animals (groups $\mathrm{C}$ and $\mathrm{E}$ ) (Table 4). After feeding the diets with no added cholesterol for 8 weeks, plasma LDL-cholesterol concentrations remained high in coconut-oil-fed animals (group B) but were markedly reduced in olive-oil-fed animals (group C). After a further 8 weeks LDL-cholesterol was reduced in both dietary groups but still remained lower in those fed on olive oil. HDL-cholesterol was significantly increased after 16 weeks of olive-oil feeding (group E) compared with group A.

Fig. 2 shows the development of atherosclerosis in these animals. In the ascending aorta the extent of atherosclerosis continued to increase in coconut-oil-fed animals even when cholesterol was omitted from the diet. By contrast, the amount of atherosclerosis in the olive-oil-fed animals remained fairly constant. The pattern of lesion development in the aortic arch was different, with evidence of regression in both coconut-oil and olive-oil-fed animals.

\section{Discussion}

The male hamster has proved a useful model of lipoprotein metabolism and displays some important advantages over other small animal species (Spady et al. 1993). Coupled with its small size and ease of handling the hamster has become a popular model of dietary effects on lipoprotein metabolism.

Significantly less work has been done on the hamster as a potential model of the development of atherosclerosis. Nistor et al. (1987) have presented a detailed study of the progression of atherosclerosis in the cholesterol-fed hamster. Feeding on a diet containing $30 \mathrm{~g}$ cholesterol $/ \mathrm{kg}$ and $150 \mathrm{~g}$ butter $/ \mathrm{kg}$ resulted in dramatic increases in LDLcholesterol which were accompanied by the development of atherosclerosis in the aortic arch. After 4 weeks of feeding, lipid deposits were visible in the aortic arch due to the appearance of lipid-laden macrophages in the subendothelium. By 4-5 months, fatty streaks were clearly visible and by $10-12$ months, lesions were proliferative with necrotic zones and $\mathrm{Ca}$ deposits. These lesions were reported to occlude up to $30 \%$ of the lumen. Extensive lesions have also been reported to develop in the coronary arteries of hamsters fed on diets rich in saturated fat and cholesterol for extended periods of time (Sima et al. 1990).

The development of atherosclerosis in the hamster has since been shown to be susceptible to a variety of pharmacological interventions (Kowala et al. 1991, 1993; Foxall et al. 1992; Otto et al. 1995) and is responsive to the antioxidant content of the diet (Parker et al. 1995). However, only one recent paper (Pitman et al. 1998) has reported regression of atherosclerosis in the hamster.
The animals used in the present study were bred within our own facility and were of the DSNI strain. We have previously shown that, in the presence of very low concentrations of dietary cholesterol $(0.05 \mathrm{~g} / \mathrm{kg})$, this strain of hamster responds to dietary saturated fats with an increase in the LDL fraction (Bennett et al. 1995; Salter et al. 1998). In the present study a diet containing a very high concentration of cholesterol $(30 \mathrm{~g} / \mathrm{kg})$ was used to induce atherosclerosis. This was done to ensure that lesions covered a significant area of the aorta such that regression might be detected on changing the diet. This atherogenic diet resulted in a dramatic increase in the plasma concentrations of VLDL-, IDL-, and LDL-cholesterol. Plasma TAG was also dramatically increased. In comparing the two studies the increase in VLDL was considerably greater in study 2 than in study 1 . The reason for this is unclear, but the use of coconut oil in the first trial and hydrogenated coconut oil in the second may have had some influence. While coconut oil contains approximately $130 \mathrm{~g}$ unsaturated fatty acids/ $\mathrm{kg}$ this is reduced to about $15 \mathrm{~g} / \mathrm{kg}$ in the hydrogenated form. This is due to the conversion of both oleic acid and linoleic acid to stearic acid (Table 1). The basic rodent chow also differed between the two experiments but both were rodent breeding diets of similar overall nutrient and fatty acid composition. The other difference was the starting age and weight of the hamsters which were significantly less in the animals used in study 2. Thus, one or more of these differences may have contributed to the difference in response seen in the two studies. The hyperlipidaemia and extent of atherosclerosis seen in the present study were not as great as in the commonly used $F_{1} B$ hybrid strain of hamster which has been shown to develop lesions after feeding cholesterol at only $0.5 \mathrm{~g} / \mathrm{kg}$ diet (Otto et al. 1995). However, we have found that the $\mathrm{F}_{1} \mathrm{~B}$ strain exhibits even greater increases in cholesterol and TAG content of the VLDL fraction on cholesterol feeding (MA McAteer, GM Benson and AM Salter, unpublished results).

The presence of atherosclerotic lesions, as demonstrated by Oil-Red-O staining was shown in both the ascending aorta, in the area of the aortic valves and on the inner curvature of the aortic arch. Generally lesions appeared earlier in the ascending aorta and were more extensive. The development of lesions at the base of the aortic sinus is also characteristic of dietary induced atherosclerosis in certain inbred strains of mice but only rarely do such lesions extend to the aortic arch in this species (Breslow, 1996). Much more widely distributed lesions are, however, seen in transgenic mouse models such as the apoE-knockout and LDL receptor-deficient mouse (Ishibashi et al. 1994; Nakashima et al. 1994).

Stein et al. (1996) have suggested that on low-cholesterol diets the high concentration of HDL relative to LDL in hamsters makes the animals resistant to atherosclerosis. We have also found that on diets containing less than about $5 \mathrm{~g}$ cholesterol $/ \mathrm{kg}$ plasma HDL-cholesterol concentrations remain higher than LDL-cholesterol and there is little evidence of the development of atherosclerotic lesions (AM Salter and EH Mangiapane, unpublished results). However, as can be seen in the present study, higher concentrations of dietary cholesterol induce increases in VLDL-, IDL- and LDL-cholesterol relative to 
HDL-cholesterol and lipid-rich lesions develop. It remains to be established which of the less dense lipoprotein fractions are contributing to the atherosclerosis. It is of note, however, that in study 2, when cholesterol was removed from the diet, VLDL-cholesterol and IDL-cholesterol concentrations fell at similar rates in both the coconut- and olive-oil-fed animals but LDL-cholesterol dropped much faster in those fed on olive oil. During this period, in the coconut-oil-fed animals, atherosclerosis continued to develop in the ascending aorta and remained relatively constant in the arch. This appears to suggest a difference in susceptibility to atherosclerosis in these regions with the ascending aorta being more sensitive to LDL-cholesterol concentrations than the aortic arch. By contrast, substantial regression was seen in both regions in those fed on olive oil, providing indirect evidence that it is the lowering of LDLcholesterol concentrations that is important. Lowering of LDL may prevent the further development of lesions and allow the HDL to promote regression.

The results of the present experiments suggest that dietary manipulation of lipoprotein concentrations can lead to regression of atherosclerosis in the hamster. At the present time we cannot say whether it is only the change in fatty acid composition of the diet which induces the reduction in atherosclerosis or whether other components of the olive oil may also have an effect. For example, the antioxidant profile of the two oils is very different, with olive oil containing over twenty times as much $\alpha$-tocopherol as coconut oil (Padley et al. 1994) and this may contribute to the regression of atherosclerosis. It would also be interesting to know whether oils rich in polyunsaturated fatty acids are more potent at reducing atherosclerosis as seen in African Green monkeys (Rudel et al. 1995). However, the present study and the recent report by Pitman et al. (1998) suggest that the hamster is potentially a very useful animal model for the further study of both the progression and regression of atherosclerosis.

\section{Acknowledgements}

The authors would like to thank the late Ms Judi Simpson for her excellent technical assistance. This work was partly supported by a contract from MAFF (CSA 2047) and a PhD studentship (M. A. M.) from the BBSRC.

\section{References}

Bennett AJ, Billett MA, Salter AM, Mangiapane EH, Bruce JS, Anderton KL, Marenah CB, Lawson N \& White DA (1995) Modulation of hepatic lipoprotein B, 3-hydroxy-3-methyl-glutaryl-CoA reductase and low density lipoprotein receptor mRNA and plasma lipoprotein concentrations by defined dietary fats. Biochemical Journal 311, 167-173.

Breslow JL (1996) Mouse models of atherosclerosis. Science 272, 685-688.

Foxall TL, Shwaery GT, Stucchi AF, Nicolosi RJ \& Wong SS (1992) Dose-related effects of Doxazosin on plasma lipids and aortic fatty streak formation in the hypercholesterolemic hamster model. American Journal of Pathology 140, 1357-1363.

Ishibashi S, Goldstein JL, Brown MS, Herz J \& Burns DK (1994) Massive xanthomatosis and atherosclerosis in cholesterol-fed low density lipoprotein receptor-negative mice. Journal of Clinical Investigation 93, 1885-1893.

Kahlon TS, Chow FI, Irving DW \& Sayre RN (1996) Cholesterol response and foam cell formation in hamsters fed two levels of saturated fat and various levels of cholesterol. Nutrition Research 16, 1353-1368.

Kowala MC, Nunnari JJ, Durham SK \& Nicolosi RJ (1991) Doxazosin and cholestyramine similarly decrease fatty streak formation in the aortic arch of hyperlidemic hamsters. Atherosclerosis 91, 35-49.

Kowala MC, Mazzucco CE, Hartl KS, Seiler SM, Warr GA, Abid S \& Grove RI (1993) Prostacyclin agonists reduce early atherosclerosis in hyperlipidemic hamsters. Arteriosclerosis and Thrombosis 13, 435-444.

Lindsey S, Benattar J, Pronczuk A \& Hayes KC (1990) Dietary palmitic acid (C16:0) enhanced HDL cholesterol and LDL receptor mRNA in hamsters. Proceedings of the Society for Experimental and Biological Medicine 195, 261-269.

Mahler VMG (1995) Coronary atherosclerosis stabilisation: an achievable goal. Atherosclerosis 118, S91-S101.

Nakashima Y, Plump AS, Raines EW \& Breslow JL (1994) ApoEdeficient mice develop lesions of all phases of atherosclerosis throughout the arterial tree. Arteriosclerosis and Thrombosis 14, $133-140$.

Nistor A, Bulla A, Filip D \& Radu A (1987) The hyperlipidemic hamster as a model of experimental atherosclerosis. Atherosclerosis 68, 159-173.

Oshima R, Ikeda T, Watanabe K, Itakura H \& Sugiyama N (1998) Probucol treatment attenuates the aortic atherosclerosis in Watanabe heritable hyperlipidemic rabbits. Atherosclerosis 137, 13-22.

Otto J, Ordovas JM, Smith D, van Dongen D, Nicolosi RJ \& Schaefer EJ (1995) Lovastatin inhibits diet induced atherosclerosis in F1B Golden Syrian hamsters. Atherosclerosis 114, 19-28.

Padley FB, Gunstone FD \& Harwood JL (1994) Occurrence and characteristics of oils and fats. In The Lipid Handbook, pp. 47223 [FB Gunstone, JL Harwood and FB Padley, editors]. London: Chapman \& Hall.

Parker RA, Sabrah T, Cap M \& Gill BT (1995) Relation of vascular oxidative stress, $\alpha$-tocopherol, and hypercholesterolemia to early atherosclerosis in hamsters. Arteriosclerosis, Thrombosis and Vascular Biology 15, 349-358.

Pitman WA, Osgood DP, Smith D, Schaefer EJ \& Ordovas JM (1998) The effect of diet and lovastatin on regression of fatty streak lesions and on hepatic and intestinal mRNA levels for the LDL receptor and HMG CoA reductase in F1B hamsters. Atherosclerosis 138, 43-52.

Rudel LL, Parks JS \& Sawyer JK (1995) Compared with dietary monounsaturated and saturated fat, polyunsaturated fat protects African Green monkeys from coronary-artery atherosclerosis. Arteriosclerosis, Thrombosis and Vascular Biology 15, 21012110.

Salter AM, Mangiapane EH, Bennett AJ, Bruce JS, Bilett MA, Anderton KL, Marenah CB, Lawson N \& White DA (1998) The effect of different dietary fatty acids on lipoprotein metabolism: concentration-dependent effects of diets enriched in oleic, myristic, palmitic and stearic acids. British Journal of Nutrition 79, 195-202.

Sessions VA \& Salter AM (1994) The effects of different dietary fats and cholesterol on serum lipoprotein concentrations in hamsters. Biochimica et Biophysica Acta 1211, 207-214.

Sima A, Bulla A \& Simionescu N (1990) Experimental obstructive atherosclerosis in the hyperlipidemic hamster. Journal of Submicroscopic and Cytologic Pathology 22, 1-16.

Spady DK \& Dietschy JM (1988) Interaction of dietary cholesterol and triglycerides in the regulation of hepatic LDL 
transport in the hamster. Journal of Clinical Investigation 81, 300-309.

Spady DK, Woollett LA \& Dietschy JM (1993) Regulation of plasma LDL-cholesterol by dietary cholesterol and fatty acids. Annual Reviews of Nutrition 13, 355-381.

Stein O, Dabach Y, Hollander G, Halperin G, Thiery J \& Stein Y (1996) Relative resistance of the hamster to aortic atherosclerosis in spite of prolonged vitamin E deficiency and dietary hypercholesterolemia. Putative effect of increased HDL? Biochimica et Biophysica Acta 1299, 216-222.

Strong JP, Bhattacharyya AK, Eggen DA, Malcom GT, Newman WP \& Restrepo C (1994) Long term induction and regression of diet induced atherosclerotic lesions in rhesus monkeys. 1. Morphological and chemical evidence for regression of lesions in the aorta and carotid and peripheral arteries. Arteriosclerosis and Thrombosis 14, 958-964.

Vesselinovitch D, Wissler RW, Fischer-Dzoga K, Hughes R \& DuBien L (1974) Regression of atherosclerosis in rabbits 1 . Treatment with low fat diet, hyperoxia and hypolipidemic agents. Atherosclerosis 19, 259-275.

White DA, Bennett AJ, Billett MA \& Salter AM (1997) Genetic determinants of plasma lipoprotein levels and their dietary response. Prostaglandins, Leukotrienes and Essential Fatty Acids 57, 455-462.

Wissler RW \& Vesselinovitch D (1990) Can atherosclerotic plaques regress? Anatomical and biochemical evidence from nonhuman animal models. American Journal of Cardiology 65, 33F-40F.

Woollett LA, Spady DK \& Dietschy JM (1989) Mechanisms whereby saturated triacylglycerols elevate the plasma low density lipoprotein concentration in hamsters. Journal of Clinical Investigation 84, 119-128.

Woollett LA, Spady DK \& Dietschy JM (1992) Regulatory effects of the saturated fatty acids $6: 0$ through 18:0 on hepatic low density lipoprotein receptor activity in the hamster. Journal of Clinical Investigation 89, 1133-1141.

Zhu B-Q, Sievers RE, Isenberg WM, Smith DL \& Parmley WW (1990) Regression of atherosclerosis in cholesterol-fed rabbits: effects of fish oil and verapamil. Journal of the American College of Cardiology 15, 231-237.

Zhu B-Q, Sun Y-P, Sievers RE, Isenberg WM, Moorhead TJ \& Parmley WW (1994) Effects of etidronate and lovastatin on the regression of atherosclerosis in cholesterol-fed rabbits. Cardiology 85, 370-377. 